\title{
La delimitación de la libertad contractual en virtud de exigencias sociales*
}

\author{
[Artículos]
}

\author{
Joaquín Emilio Acosta Rodríguez ** \\ José Manuel Gual Acosta ${ }^{* * *}$
}

Recibido: 10 febrero de 2021

Aceptado: 6 de mayo de 2021

Citar como:

Acosta Rodríguez, J. E. y Gual Acosta, J. M. (2021). La delimitación de la libertad contractual en virtud de exigencias sociales. Revista IUSTA, (55).

https://doi.org/10.15332/25005286.6850

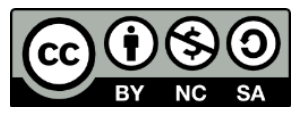

\section{Resumen}

En este artículo se presenta el impacto que los movimientos sociales de la segunda mitad del siglo XIX tuvieron en la doctrina de contratos del siglo XX. Se propone un análisis de esta influencia para reformular el problema de la libertad contractual, a la luz del Estado social de derecho,

\footnotetext{
* El presente artículo es resultado del proyecto de investigación: "La constitucionalización del derecho de contratos" del grupo de investigación Teoría del Derecho y de la justicia, gestionado en la Universidad La Gran Colombia, en colaboración con el Grupo de Derecho Privado y del Proceso de la Universidad Libre, Colombia.

** Doctor en Derecho de los Negocios, Université de Bordeaux, Francia. Docente de la Universidad Gran Colombia. Correo electrónico: joaquin.acosta@ugc.edu.co;ORCID: https://orcid.org/0000-0002-6849-1577

*** Doctor en Derecho Civil, área Responsabilidad, calificada con la máxima nota summa cun laudem, por la Scuola Sant Anna di Pisa, Italia. Docente de la Universidad Libre, Colombia. Correo electrónico: josegual2@gmail.com, josem.gual@unilibre.edu.co; ORCID: https://orcid.org/0003-0891-3691
} 
y el correlativo redimensionamiento del orden público y las buenas costumbres. Además, se recurre a un análisis histórico-originalista para repensar la fuerza obligatoria del contrato.

Palabras clave: buenas costumbres, cuestión social, libertad contractual, orden público.

\title{
The delimitation of freedom of contract by virtue of social demands
}

\author{
Abstract \\ This article presents the impact that social movements of the second half \\ of the nineteenth century had on the doctrine of contracts in the \\ twentieth century. An analysis of such influence is proposed in order to \\ reformulate the problem of freedom of contract, in light of the Social \\ Rule of Law, and the correlated reshaping of public order and good \\ customs. In addition, a historical-originalist analysis is used to rethink \\ the binding force of the contract.
}

Keywords: good customs, social issue, freedom of contract, public order.

\section{A delimitação da liberdade contratual em virtude de exigências sociais}

\section{Resumo}

Neste artigo, é apresentado o impacto que os movimentos sociais da segunda metade do século XIX tiveram na doutrina de contratos do século XX. É proposta uma análise dessa influência para reformular o problema da liberdade contratual, à luz do Estado social de direito, e o correlativo redimensionamento da ordem pública e dos bons costumes. 
Além disso, recorre-se a uma análise histórico-originalista para repensar a força obrigatória do contrato.

Palavras-chave: bons costumes, questão social, liberdade contratual, ordem pública.

\section{Introducción}

\section{La deconstrucción de la autonomía de la voluntad}

En virtud de la promulgación del Estado social de derecho por no pocas constituciones de Europa, África o América Latina - entre estas la colombiana $^{1}-$, se impuso una concepción social de los vínculos contractuales, como ya lo ha reconocido ampliamente la Corte Constitucional (Sentencia C-66o/96, Colom. ${ }^{2}$ ) o la Corte Suprema de Justicia (Sentencia de octubre 19 de 2011)3. Este reconocimiento genera numerosos interrogantes, tales como: ¿cuáles son las implicaciones exactas de esta concepción más cercana a lo social del derecho de contratos? y ¿cuáles son sus límites? Para responder estas preguntas es necesario explorar la denominada “deconstrucción de la autonomía de la

1 "Colombia es un Estado social de derecho, organizado en forma de República unitaria, descentralizada, con autonomía de sus entidades territoriales, democrática, participativa y pluralista, fundada en el respeto de la dignidad humana, en el trabajo y la solidaridad de las personas que la integran y en la prevalencia del interés general" (C.P., 1991, art. 1, Colom.).

2 "En conclusión, mal puede considerarse a la autonomía de la voluntad como un poder omnímodo en cabeza de los particulares; los múltiples límites que se le imponen, la reducen a un simple ejercicio de potestades reglamentarias que el legislador otorga a los ciudadanos" (C.C., Sentencia C-660/96, Colom.).

3 "Por lo común, las partes están llamadas a prevenir, evitar y corregir el desequilibrio prestacional. En efecto, la autonomía privada dispositiva o libertad contractual, estructural e indisociable de la democracia, el 'Estado social de derecho' y principio rector de la contratación (Preámbulo, arts. 20,13,14,16, 28, 58, 59 a 66, 78, 82, 94,150 [19] y [23], 332, 333, 334, 335, 373, Constitución Política; cas. civ. sentencia de 30 de agosto de 2011, exp. 11001-3103-012-1999-01957-01) faculta a las partes para 'disciplinar el contenido del negocio jurídico, conforme a sus necesidades, conveniencia, designios, intereses disponibles, orden público, buenas costumbres, función práctica económica o social útil, relatividad de los derechos, paridad, buena fe, lealtad y corrección exigibles"' (C.S.J., Sentencia SC284-2006, Colom.). 
voluntad”. En efecto, si el siglo XIX dio lugar al auge de la autonomía de la voluntad en el derecho de contratos, poco después, a comienzos del siglo $\mathrm{XX}$, fue el contrato mismo el que debió responder a un nuevo contexto. La doctrina ha tenido a bien erigir contra esta teoría un pliego de cargos implacable (Picot, 1989; Izorche, 1989). La mayor parte de los autores de la época (Duguit, 2018 [1912]; Gounot, 1912) intentaron deconstruir el dogma del individuo todopoderoso (Gahdoun, 2015), bajo el argumento que la autonomía de la voluntad ya no es más la piedra angular del derecho de contratos (Gual, 2015), y como tránsito hacia una libertad "social” como medio para alcanzar el "bien común". De esta manera, a comienzos del siglo XX el contrato enfrentó su primera crisis, especialmente por Saleilles (1901) y Duguit (2018 [1921]), incluso antes de Gounot (1912), en vísperas de la Primera Guerra Mundial (Waline, 1949). La desconfianza continuó alentada por el "solidarisme contractuel"4 (Cedras, 2003; Durkheim, 1930). Los instrumentos jurídicos serán canalizados a través de una relectura de los artículos 1134 y 1135 del Código Civil francés - disposiciones que inspiraron los artículos 1602 y 1603 del Código Civil colombiano - relativos a las nociones de buena fe, equidad contractual, abuso del derecho e incluso cláusulas abusivas (Acosta y Valderrama, 2015). Así, al postulado que pretendía que las personas son iguales y en este sentido cualquier acuerdo de voluntades conduce a la justicia, se ha replicado que los contratantes son fundamentalmente desiguales (Terré, Simler y Lequette, 2013). De esta manera, muy lejos de conducir a vínculos equilibrados, la libertad contractual sería el instrumento que permitiría al fuerte imponer su ley al

\footnotetext{
${ }^{4} \mathrm{El}$ "solidarisme contractuel" designa una corriente doctrinal francesa que reclama una decisiva toma de conciencia de la desigualdad en las convenciones. Se apoya en parte en las ideas de Durkheim, quien la evocó en su obra De la division sociale du travail (1930 [1893]).
} 
débil, lo que desata un desafío importante para la autonomía de la voluntad.

\section{El cuestionamiento a la autonomía de la voluntad privada}

Incluso al tiempo que la doctrina se erigía en auténtico sistema, las concepciones políticas ligadas a un liberalismo absolutista comenzaban a tambalearse. La sociedad y el derecho se transformaban, y una doctrina contraria iba a aparecer (Vargas, 2018). En efecto, Europa continental, después del primer tercio del siglo XIX, y a consecuencia de la industrialización, asistió al nacimiento de nuevas preocupaciones sociales (Villalba y Fernández, 2020). La concepción del contrato que el código civil elaboró correspondía perfectamente a la mayor parte de las relaciones económicas y sociales que se entablaban entre particulares (Lévy y Castaldo, 2002). El contrato en esta época solía celebrarse entre personas de iguales condiciones, o más bien, se pretendía creer esta ficción (Gazzaniga, 1992). Además, finalmente se constató que las personas se orientan naturalmente hacia las actividades más rentables, las cuales no son necesariamente las más útiles (Terré, Simler y Lequette, 2013). En suma, mucho se ha escrito y analizado sobre este principio de la autonomía de la voluntad (Gounot, 1912). Por lo tanto, concebir una voluntad perfectamente autónoma es cuando menos ilusorio (Ranouil, 1980). Sin embargo, si la voluntad se fundamentara en una determinada moral divina, esta también podría adherirse a una particular idea de la justicia para positivizarse en la ley, pero jamás de una manera absolutamente autónoma. Es por ello que el Conseil Constitutionnel no tuvo grandes dificultades para deshacerse de la autonomía de la voluntad, con su decisión del 20 de marzo de 1997 (CC 97-388, Rec. p. 31, esp. n. ${ }^{\circ} 48$ : 
[...] ne résulte ni de l'article 4 de la Déclaration des droits de l'homme et du citoyen ni d'aucune autre norme de valeur constitutionnelle un principe constitutionnel dit de "l'autonomie de la volonté"; que les griefs allégués par les requérants ne peuvent dès lors qu'être rejetés.

Esto corresponde a la culminación de un proceso histórico que remonta sus raíces a la aparición del derecho laboral.

\section{La aparición del derecho laboral}

La legislación del trabajo es, ante todo, la que aportó la más grande contradicción a las teorías liberales (Lévy y Castaldo, 2002). Abusos escandalosos fueron denunciados en el trabajo de las minas y fábricas por la célebre investigación del Dr. Villermé (1837-1840), la cual reveló, por ejemplo, que niños de seis años trabajaban en lo profundo de las minas doce horas al día, cuando menos. En ese momento, el célebre jurista, académico, orador y sacerdote dominico Lacordaire lanzó desde el púlpito de la catedral parisina de Notre-Dame esta fórmula admirable: "Entre el fuerte y el débil, entre el rico y el pobre, es la libertad la que oprime, es la ley la que libera"5. Tal proclama fue escuchada por lo mejor de la intelectualidad francesa, entre quienes se encontraban Alejandro Dumas, Balzac, Chateaubriand, Lamartine, Victor Hugo o Tocqueville, entre otros, y aquellos que no asistían a las misas leían lo que la prensa registraba de estas. En síntesis, los redactores del Código Civil no pudieron prever la mutación profunda que marcó el fenómeno contractual a partir de la segunda mitad del siglo XIX (Chevreau, Mausen y Bouglé, 2007). Luego de la investigación de Villermé fue votada la primera ley social, el 22 de marzo de 1841: su objetivo fue "limiter le travail des enfants dans les manufactures, usines et ateliers" (limitar el trabajo infantil en las

\footnotetext{
5 Traducción propia del original: "Entre le fort et le faible, entre le riche et le pauvre, c'est la liberté qui opprime, c'est la loi qui affranchit".
} 
empresas, fábricas y talleres). Sin embargo, pasaron más de siete años, y la Revolución de 1848, para que se adoptara otra medida: el decreto del 9 de septiembre de 1848, el cual instituiría la jornada laboral de máximo doce horas. Otras leyes intervinieron posteriormente, a pesar de los teóricos "maniacos de la libertad". A continuación, se expondrá inicialmente el declive de la autonomía de la voluntad, para luego dirigir la investigación hacia el neocausalismo.

\section{El declive de la autonomía de la voluntad}

\section{La disminución del papel de la voluntad en los contratos}

La reducción del papel de la voluntad en los contratos fue detectada, inicialmente, en los contratos de adhesión - la expresión pareciera haber sido acuñada por Saleilles (1901) - , Hauriou (1906) considera que tales acuerdos "solo tienen de contrato el nombre... igual sería discutir con fonógrafos"6. Así surge el interrogante, que dividirá a los juristas, de si se trata verdaderamente de un contrato. Para Saleilles (1901), se trata de un acto unilateral, en la medida en que los elementos esenciales del contrato constituyen el hecho de uno solo (el empleador, la compañía de seguros, la sociedad de transporte, etc.), mientas que la contraparte se limita a adherirse a cláusulas que se escapan de su control. Por el contrario, Dereux (1910), en su tesis doctoral, defendió la concepción contractual de la adhesión a la oferta, e insistió sobre este punto en la Revue Trimestrielle de Droit Civil (1910) para responder a las objeciones del maestro Hauriou. Durante más de treinta años, esta cuestión ocupó a la doctrina (Domergue, 1935; Missol, 1934; De Saint-Rémy, 1928; Pichon, 1913; Portier, 1909; Dollat, 1905). El balance de este debate es la constatación que, si bien en la

\footnotetext{
${ }^{6}$ Traducción propia del original: " $n$ 'ont du contrat que le nom... autant vaudrait discuter avec des phonographes".
} 
época del Código Civil la mayoría de los contratos se celebraban luego de una negociación que permitía a las partes establecer sus elementos esenciales, e incluso accidentales, la concentración económica y comercial engendró disparidades considerables en los campos económico, técnico y jurídico (Robaye, 2000). En este sentido, la parte más fuerte establece, en su único interés, un modelo contractual al cual su contraparte solo puede adherirse (Berlioz, 1976).

De igual manera, una ficción determina que los reglamentos de los talleres se consideren tácitamente incluidos en el contrato de trabajo y, por ello, se reputan aceptados. Estos se organizan más tarde, durante las convenciones colectivas, celebradas no por cada trabajador, sino, en su nombre, por los representantes sindicales. En este contexto, la primera ley se promulgó el 25 de marzo de 1919. La libertad contractual también tendía a difuminarse (Lévy y Castaldo, 2002): libertad de contratar, e incluso de no contratar. En cuanto a la primera, una reglamentación imperativa se multiplica, lo que la vuelve inmensa y minuciosa; la noción de orden público es considerablemente expandida por la jurisprudencia. Frente a la libertad de no contratar se encuentran los contratos forzados (Hinestrosa, 2015): por ejemplo, el arrendatario debe estar asegurado, o bien, a menudo, un propietario no puede dejar un local vacante, etc. La libertad que subsiste es la de escoger su contraparte. Finalmente, incluso en la formación de los contratos, el papel exclusivo del consentimiento retrocede, lo que permite hablar de un renacimiento del formalismo (Moeneclaye, 1914).

En suma, en el momento mismo en que los adeptos de la autonomía de la voluntad, embebidos por una lógica abstracta, desarrollaban sus teorías, otros juristas tomaban conciencia de una realidad social y jurídica en oposición flagrante y creciente con sus dogmas. Este debate abrió la historia del contrato en el siglo XX (Louis-Lucas, 1939; Dikoff, 1938; 
Barreyre, 1937; Roussel, 1936; Gaudin de Lagrange, 1935; Capitant, 1934 y 1922; Perreau, 1934; Duguit, 2018 [1920]).

\section{La crítica doctrinal de la autonomía de la voluntad}

La tesis de la autonomía de la voluntad, cabe resaltarlo, ha encontrado siempre resistencias, organizadas en el último cuarto del siglo XIX, en paralelo a las exageraciones de la teoría (Lévy y Castaldo, 2002). Las objeciones estuvieron frecuentemente inspiradas por la ideología política y social, de inspiración socialista, o al menos socializante, y por el cristianismo social. Si la libertad era la regla es debido a que la igualdad se consideraba un principio absoluto (Berthiau, 1999). Las condiciones del contrato eran libremente discutidas entre los individuos. Sin duda, tratándose del arrendamiento, prestación de servicios o sociedad, la admisión del principio era cada vez más difícil, sin embargo, resistía (Gazzaniga, 1992). No obstante, debido a la industrialización, se asiste a una cierta colectivización de las relaciones negociales.

En Alemania - donde surgió la idea de autonomía y el dogma de la voluntad - los juristas se pasaron a la doctrina opuesta, criticaban el Willendogma, al considerar que es falso que la voluntad sea la esencia del acto jurídico. Algunos hicieron un esfuerzo, por cierto controversial, de sustituir la voluntad -Willenserklärung, término que figura en el Bürgerliches Gesetzbuch (BGB) o Código Civil de 1900 - como eje y fundamento del lazo contractual. Otros intentaron una rehabilitación del formalismo: "la forme es el paladio de la libertad" escribió el gran jurista Ihéring (1969), ya que impide la ligereza y correlativamente la arbitrariedad. Este mismo autor indicó que "la justicia se encuentra por encima de la libertad" (1877). Por su parte, en la encíclica Rerum novarum de 1891, el papa León XIII proclamó que la justicia natural 
prima sobre la libertad de los contratantes. La teoría individualista del contrato parece pasada de moda (Gazzaniga, 1992).

En Francia, Leroy publicó, en 1898, De l'esprit de la législation napoléonienne y, en 1904, Códe civil et droit nouveau. En estas obras el autor denuncia la ilusión que se vincula a la voluntad creadora del contrato. El ataque en regla se desata poco después: este se encuentra principalmente en la obra de Saleilles (1901), Duguit (1920), Hauriou (1927) y, particularmente, Gounot (1912). Este último efectúa una refutación enérgica de la teoría de la autonomía de la voluntad, basada inicialmente en su punto de partida individualista, calificado de "robinsonisme social", en clara alusión al aislacionismo de Robinson Crusoe, el célebre náufrago; y luego pasa a desvirtuar que la voluntad sea el fundamento del derecho. La voluntad, indica Gounot, está al servicio del derecho, no al contrario. A renglón seguido, critica la voluntad como fundamento de los contratos: su fuerza deriva de su función en el mundo, en aras del bien común (Mekki, 2004). La libertad únicamente proporciona una presunción de justicia, mas no una certeza. En respuesta a Fouillé (1885; 1909), Gounot afirma que la justicia en el contrato solo existe si se verifica una equivalencia de prestaciones. Finalmente, resalta los peligros de la libertad contractual, que puede convertirse en un instrumento de opresión, en este sentido, resalta que ha sido menester promulgar una legislación laboral.

Una vez que la voluntad ya no pudo explicar más - por sí sola - la fuerza obligatoria del vínculo contractual, fue necesario encontrarle un substituto (Gahdoun, 2008). A partir de las ideas kelsenianas se acordó que si el contrato es obligatorio, esto se debe a que una norma superior lo autoriza. Así las cosas, la libertad contractual está condicionada por el derecho positivo existente. En síntesis, decir que únicamente la voluntad individual puede crear obligaciones y considerar que solo ella vincula es excesivo. Tal 
radicalismo implica admitir que el contrato es todo. Igualmente, se han extraído consecuencias abusivas, ya que tal contrato se encuentra encerrado por la misma voluntad que lo ha creado (Chabas, 1931; Ponceau, 1931; Tison, 1931). De esta manera, el error se ha extendido excesivamente: por ejemplo, la lesión no se admite - salvo excepción- así provoque un desequilibrio intolerablemente injusto entre las partes. Pero precisamente debido a que las partes lo han querido, este desequilibrio debe considerarse justo. Tal concepción deja demasiado espacio a la voluntad individual. Asimismo, gracias a esta definición estricta de la autonomía de la voluntad, la interpretación del contrato es extremadamente limitada.

Las complejidades de la teoría de la causa no tienen otro origen que la exaltación del individualismo. La búsqueda psicológica de los motivos y móviles no se explicaría sin ella. Nada de sorprendente tiene que a finales del siglo XIX apareciera la corriente anticausalista, anunciada por las tesis de Laurent (1887). Para Planiol (1905), como para Huc (1894), la causa se confunde con el objeto. Para Duguit (2018 [1920]), tales especulaciones carecen de interés. Sin embargo, en esa época todo se discutía (Gazzaniga, 1992). A las críticas de los anticausalistas responden aquellos que defienden la causa, lanzando multitud de argumentos (Maury, 1920; Dubreueil, 1919; Louis-Lucas, 1918; Gaudemet, 1898; Colin, 1897).

\section{El neocausalismo}

En 1923, Henri Capitant publicó un texto que tuvo gran impacto (Lévy y Castaldo, 2002), dedicado a la defensa de la teoría de la causa (Capitant, 1923), que constituyó una auténtica síntesis de todas las opiniones favorables a esta corriente (Gazzaniga, 1992). Así, respecto a la afirmación de los anticausalistas, según la cual un buen número de sistemas jurídicos se desenvuelven sin la noción de causa, Capitant se pregunta si, en el 
fondo, otras instituciones de tales ordenamientos no serían algo equivalentes, es decir, no responderían a la misma necesidad. Con esto se entabla un nuevo llamado al derecho comparado.

\section{Los antiguos derechos griego y orientales}

Pareciera reinar un principio que, sin duda jamás ha sido expresado, pero que implícitamente explica no pocas soluciones. Según los trabajos de los eruditos contemporáneos, se trataría del "principio de contrapartida necesaria”. Este principio tácito domina el derecho de obligaciones y el régimen de la transferencia de la propiedad. La propiedad de un bien solo es transferida por el pago (al menos parcial) del precio; la deuda del precio tiene como contrapartida la entrega de la cosa: la de quien presta (a título de comodato o mutuo), el bien prestado y la correlativa obligación de restitución, sea del mismo bien o de su equivalente según el caso. El consensualismo puro no existe.

\section{El derecho inglés}

Desde la época medieval, en Inglaterra se aceptaba el principio quid pro quo (algo a cambio de algo) o una valuable consideration (la cual podría traducirse como "compensación de valor"). De esta manera, el deudor se encontraba obligado, no por haber prometido, sino por haber recibido. Esta compensación "representando valor" está considerada como el precio por el cual se obtiene la promesa de la contraparte: acto o abstención, o incluso promesa de acto o de abstención, ella representa en todo caso un beneficio para el deudor, o un detrimento para el acreedor. Por lo tanto, la valuable consideration es la contraprestación o una promesa de esta. Así 
se encuentra, bajo otra forma, la idea de contrapartida (Lorenzen y Ernest, $1919)^{7}$.

\section{El derecho alemán}

Es menester reconocer que el BGB de 1900 apenas se preocupaba de la justicia conmutativa. En efecto, este texto se atuvo a una concepción puramente formal de la equivalencia de las prestaciones y la consideraba adquirida una vez que las partes se pusieran de acuerdo sobre los beneficios a intercambiar (Pédamon, 2004). Pero debido a los trastornos que sufrió Alemania luego del fin de la Primera Guerra Mundial, a partir de la noción de "cláusulas generales", los tribunales se dedicaron a remediar los desequilibrios de los contratos inspirándose de la famosa teoría del profesor Oertmann, denominada "Wegfall der Geschäftsgrundlage" (desaparición del fundamento del acto jurídico) (Ferrand, 1997), la cual también dio lugar a la noción de ausencia originaria del fundamento contractual, asimilada al cambio radical de circunstancias. Las cláusulas generales permitieron a los tribunales imponer a las partes una completa red de obligaciones accesorias (Nebenpflichten). Adicionalmente, el § 138 inc.2 del BGB contempla una hipótesis particular de contrariedad a las buenas costumbres: la usura (wucher), que en Alemania cuenta con un sentido más extendido que en Francia o Colombia, entendida como el supuesto de obtener el compromiso de beneficios patrimoniales en flagrante desproporción con su propia prestación debido a la explotación de la necesidad, de la

\footnotetext{
7 Esta contrapartida no corresponde, sin embargo, a una equivalencia de valores. La lesión no interviene aquí para derribar al contrato, ya que incumbe a las partes, y no al juez, el defender sus intereses. Igualmente, se admite que la consideration pueda estar reducida a un símbolo: una libra (e incluso, un grano de pimienta), como contrapartida a un compromiso importante. Para nada se exige que la contraprestación sea del mismo valor que la obligación: solamente es imperativo que exista.
} 
inexperiencia e incluso de la debilidad de juicio o carácter de la contraparte.

\section{Perspectivas para los derechos de tradición francesa}

Estos pocos elementos de historia comparatista permiten volver al nudo problemático de nuestro hilo. La teoría de la causa, tan bizarramente construida, oculta la misma preocupación profunda: el consentimiento, la voluntad en sí misma no es suficiente; es necesario ir más allá de las apariencias, indagar porqué la declaración de voluntad ha sido otorgada y expresada. Dicho en otros términos, ha de preguntarse cuál ha podido ser la contrapartida de la obligación asumida. De esta manera, nos topamos con un sentimiento profundo de justicia conmutativa, cuyas aplicaciones se encuentran en todo el derecho patrimonial. La teoría de la causa es la expresión, más o menos desafortunada, de la preocupación por la contrapartida en el mundo de los contratos y negocios. Esta atempera el consensualismo y el culto a la voluntad autónoma, la cual, sin una mínima justicia conmutativa, no resulta aceptable. La crítica radical de los anticausalistas no ha tenido eco en la jurisprudencia francesa, donde los tribunales continúan haciendo uso de la causa con el propósito de hacer reinar un mínimo de equidad y moralidad en el mundo de los contratos. El neocausalismo, presente desde la Primera Guerra Mundial, corresponde en gran medida a la reacción de los juristas cristianos al materialismo. Se le encuentra netamente en el resurgimiento del interés por el estudio del derecho natural (Gazzaniga, 1992). Se ve que la evolución de las ideas va en todos los sentidos. Tales realidades van a alimentar las reflexiones de los privatistas franceses, algunos de los cuales deseaban una revisión radical del Código Civil, y otros, como Planiol y Gaudement, eran partidarios de una reforma más moderada. De cualquier manera, el 
anticausalismo ha quedado sin eco en la jurisprudencia francesa, tal como se expuso anteriormente.

\section{¿Hacia un neoanticausalismo?}

Cien años más tarde, un sector de la doctrina francesa formuló nuevamente un discurso resueltamente anticausalista, en nombre de consideraciones políticas y técnicas. Entre las políticas se encontraba la apertura de Francia a Europa, y especialmente su participación en la elaboración de un derecho europeo de contratos, lo que exigiría que la noción de causa, ignorada por numerosos juristas europeos, fuera abandonada (Fabre-Magnan, 2008; Mazeaud, 2008). Las consideraciones técnicas señalaban que dos siglos después de su consagración por el Código Civil, la noción de causa revestiría una complejidad tal que se habría vuelto ininteligible, por lo que podría ser beneficiosamente remplazada mediante la utilización de otros instrumentos jurídicos (Lagarde, 2007). Estas corrientes recuerdan que la Corte de Casación francesa ha establecido recientemente que la concepción de la causa de las obligaciones contractuales acogida por el derecho francés no es, en todos sus aspectos, de orden público internacional (Corte Casación, D.2011.2518, Fran.).

Ahora bien, ciertamente la reforma al derecho francés de contratos, operada por l'ordonnance $n .{ }^{\circ}$ 2016-131 du 10 février 2016 portant réforme du droit des contrats, du régime général et de la preuve des obligations, habría suprimido la noción de causa (Art. 1131 s. C. civ., Fran.) como requisito de existencia y validez de los contratos; tal reforma podría ser interpretada como la eliminación de la causa en el derecho galo ${ }^{8}$. Sin

\footnotetext{
${ }^{8}$ En efecto, el Artículo 1128 del Code, tal como resultaría en virtud de l'ordonnance de reforma al derecho galo de contratos, dispone que en adelante: "Sont nécessaires à la validité $d^{\prime}$ un contrat: $1^{\circ}$ Le consentement des parties; $2^{\circ}$ Leur capacité de contracter; $3^{\circ}$ Un contenu licite et certain".
} 
embargo, el rapport au Président de la République explica que en realidad se trata simplemente de una eliminación formal para facilitar los procesos de construcción de un derecho europeo de contratos mediante la armonización de los diferentes regímenes nacionales de ese continente, lo cual evidentemente también compete al derecho francés:

[...] el abandono formal de la noción de causa, que ha suscitado varios debates, permitirá a Francia acercarse a la legislación de numerosos derechos extranjeros, al tiempo que se consagra en la ley [francesa] sus diferentes funciones, incluyendo la de reequilibrio del contrato, que la jurisprudencia le había asignado. ${ }^{9}$

De esta manera, si la palabra "cause" ha sido suprimida del Code, sus funciones esenciales son mantenidas por l'ordonnance, en textos dispersos de la reforma francesa. En definitiva, se constata que, a pesar de la supresión de la noción de causa, l'ordonnance de reforma pareciera mantener su espíritu. No obstante, lejos de simplificar las cosas, deberemos estar atentos a la interpretación de la jurisprudencia sobre las nuevas disposiciones, particularmente, las nociones de "contenu" (contenido) y de "but" (objetivo) contractuales ${ }^{10}$.

\footnotetext{
9 Traducción propia del original: "I'abandon formel de la notion de cause, qui a suscité de nombreux débats, permettra à la France de se rapprocher de la législation de nombreux droits étrangers, tout en consacrant dans la loi les différentes fonctions, dont celle de rééquilibrage du contrat, que la jurisprudence lui avait assignées" (http://actu.dalloz-etudiant.fr/a-la-une/article/suppression-de-la-cause-reforme-dudroit-des-contrats-du-regime-general-et-de-la-preuve-deso/h/fe09f919390662f42623c56689c43919.html).

10 Para ampliar la información al respecto, véanse los artículos 1162, 1169, 1170 y 1186 del nuevo Code, reformados por l'ordonnance $n^{\circ}$ 2016-131 du 10 février 2016 portant réforme du droit des contrats, du régime général et de la preuve des obligations, que entraron en vigor desde el 1 de octubre de 2016, disponibles en: https://www.legifrance.gouv.fr/affichTexte.do?cidTexte=JORFTEXT000032004939\&cat egorieLien $=$ id
} 


\section{La salvaguarda contemporánea de la causa}

$\mathrm{Al}$ neoanticausalismo se le ha replicado que la causa es conocida por todos los sistemas que se han inspirado del derecho francés: en Europa, pero particularmente en América Latina y en Medio Oriente, y que no será abdicando de sus propias tradiciones como el derecho francés podrá esperar conservar su influencia (Catala, 2008; Ghozi y Lequette, 2008). Adicionalmente, al margen de este argumento un tanto chauvinista, no resulta razonable abandonar un instrumento que los tribunales franceses emplean intensivamente (Catala, 2005), lo que daría testimonio de su utilidad en cuanto que herramienta de control, a tal punto que la causa está actualmente consagrada por la jurisprudencia administrativa francesa (Chénédé, 2008). Si la noción es compleja, se debe esencialmente a un exceso de sofisticación doctrinal (Terré, Simler y Lequette, 2013): numerosos autores que se dedicaron a obscurecerla inicialmente, demandan actualmente su desaparición. Es posible devolverle a la causa su claridad si se retoman los fundamentos de la noción tal como la doctrina y la jurisprudencia los identificaron en el pasado.

De esta manera, el famoso fallo Chronopost (CC, s. Com., 22 oct. 1996, Defrénois, 1997, 333, obs. D. Mazeaud, Fran.) ha sido objeto de vivas críticas por haberse basado en las nociones de "obligation essentielle" y causa, como augurio, según algunos estudiosos, de una política jurisprudencial poco respetuosa de la libertad contractual y de la seguridad jurídica, contraria a la tradición jurídica francesa (Sériaux, 1997). Por el contrario, otros autores asumen una posición contraria, donde la jurisprudencia francesa se muestra fiel a la herencia intelectual de los autores de comienzos del siglo XX, al delimitar de una manera más clara la libertad contractual para restaurar un cierto equilibrio contractual, y de esta manera obtener una libertad contractual "ilustrada" (Jamin, 2003). 


\section{De la crítica a la autonomía al declive del individualismo contractual}

Si bien la tesis de Gounot no puso fin a la discusión, pues la controversia continúa, sí tuvo un rotundo impacto y consiguió discípulos y continuadores que criticaron el dogma de la autonomía de la voluntad (Rouhette, 1965; Waline, 1949; Josserand, 1927).

En efecto, la autonomía de la voluntad prohibió el reconocimiento del abuso del derecho: fue inadmisible que la ley de las partes pudiera engendrar abusos. Sin embargo, en la actualidad está claro que determinados contratantes pueden abusar de su situación. Es precisamente en la época en que Josserand desarrolla la teoría del abuso del derecho, en parte como reacción contra las consecuencias de la autonomía de la voluntad. A ese primer grupo de críticas se agrega otro que se refiere al fundamento mismo del principio. En efecto, la autonomía de la voluntad nació junto con la filosofía individualista y liberal del siglo XIX. Al final de ese periodo, la sociedad es más grande que el individuo, el deber social prima sobre el interés privado. Las críticas no vienen exclusivamente del socialismo, sino también del catolicismo social. El primer crítico (Saleilles), en aras de concluir que la voluntad no lo es todo, demuestra la necesidad de tomar en cuenta la voluntad declarada: lo que las partes han querido es menos importante que lo que ellas han declarado querer. Esta concepción tiene como objetivo y resultado restringir en una medida, más o menos grande, la independencia, la autonomía del individuo. Posteriormente, las ideas serán retomadas y radicalizadas por juristas provenientes de horizontes diversos y que albergan concepciones muy diferentes de lo jurídico. De esta forma, el maestro Duguit (2018 [1912]), para quien el derecho es una función social, considera que la autonomía de la voluntad - concebida como el poder de querer jurídicamente- está en oposición con las tendencias socialistas y asociacionistas. Por su parte, Gounot inspira su crítica en el papa León 
XIII. Louis-Lucas (1939) retoma las ideas de Saleilles y demuestra que la voluntad individual que se ha denominado autónoma y libre no es ni una cosa ni la otra. La declaración de voluntad es más importante que la voluntad misma: el contrato es obligatorio menos por haber sido sólidamente querido que por haber sido correctamente querido.

\section{¿Hacia el declive del contrato?}

El debate doctrinal permite identificar restricciones exteriores impuestas por el interés general. El contrato se "publicita" (publicise), como dice Josserand (1927): el Estado impone determinadas cláusulas y el legislador impone al juez que interprete el contrato en un sentido favorable a tal o cual categoría de contratantes (los deudores insolventes), por lo tanto, el contrato se desarrolla en "colaboración con el legislador" (Louis-Lucas, 1939). Se puede dudar del principio, hasta el momento absoluto, de la inmutabilidad de las convenciones, pues como la propiedad, el contrato cambia. Las medidas se multiplican, se habla entonces de "dirigisme contractual" (Josserand, 1927). En el periodo de entreguerras, Josserand (1927), resaltando el elemento social -abuso del derecho, teoría de los móviles, enriquecimiento sin causa-, denuncia que el derecho civil está en peligro, que el nuevo orden jurídico que se instaura es esencialmente económico y que el derecho privado se vuelve social. De hecho, se preocupa, al afirmar que el contrato se vuelve cada vez menos contractual, no obstante, sigue defendiendo la concepción misma de contrato: legal, forzado e impuesto (Morel, 1950; Durand, 1944); en otras palabras, poco importan los riesgos que conlleva este sistema, siempre hay un contrato (Picard, 1950).

Por su parte, Ripert adopta otra posición, al afirmar que la moral debe seguir siendo el fundamento mismo del contrato, un rasgo clásico en su exposición de las doctrinas. El autor critica vigorosamente la influencia de 
la legislación de los años treinta que, animada por un aire "solidarista" o "humanitarista" ya no se puede considerar como derecho. De esta manera, las numerosas medidas para proteger a los más desfavorecidos crean una justicia de clase, base de la injusticia, como expone en su célebre crónica "Le droit de ne pas payer ses dettes" (1936). Ripert ve y anuncia el "déclin du contrat", que consiste en una decadencia de la soberanía del contrato, que se acentúa rápidamente en la actualidad. Como lo notará Savatier (1964), Ripert ya no reconocía más el derecho civil que había aprendido y enseñado. Como afirma el profesor Gazzaniga (1992), basta con analizar el grueso de las tesis doctorales sustentadas en los años treinta y los estudios ofrecidos a Gény y a Capitant, así como los Mélanges Ripert, para darse cuenta de que el contrato está siempre de moda.

\section{El fortalecimiento del marco restrictivo}

A finales del siglo XX, el derecho contractual francés experimentó una nueva crisis (Jamin y Mazeaud, 2003), que la doctrina francesa ha abordado desde la parte más débil. A partir del Artículo 6 del Código Civil francés, el cual dispone que las convenciones no pueden derogar las leyes que interesan al orden público, la doctrina del siglo XIX enseñó que la libertad contractual solo puede ser limitada por el legislador (Acosta, 2018). Exaltando el poder de las voluntades individuales y temiendo la arbitrariedad de los jueces, se pretendió restringir los poderes de estos últimos. De manera que correspondía, según esta concepción, únicamente a la ley decir lo que es de orden público y lo que no. Sin embargo, el orden público es una noción cuya definición ha dado lugar a numerosas controversias (Julliot de la Morandiere, 1939). No obstante, se sabe que, a semejanza de las buenas costumbres, las dos nociones constituyen prohibiciones sociales que restringen la libertad contractual, a través de normas con contenido indeterminado (Ghestin, 1984), estándares que no 
responden a ninguna definición precisa y que necesitan frecuentemente del apoyo de los jueces para ser concretadas (Hauser, 2003). En cuanto que noción imprecisa a cargo la defensa de los intereses esenciales de la sociedad, el orden público debe ser adaptado a las necesidades de la época y a las situaciones particulares de cada sociedad. De esta manera, la jurisprudencia francesa ha admitido que una convención que no desafía ningún texto preciso puede no obstante ser contraria al orden público, cuando menos si su objeto se encuentra en contradicción con los principios fundamentales del derecho, así como de la organización social (Corte Casación francesa, s. Com., Civ., 4 déc. 1929, S. 1931.1.49 note P. Esmein, in Grands Arrêts, t. 1, $\mathrm{n}^{\circ}$ 13) ${ }^{11}$.

Es bien sabido que el Estado-policía del siglo XIX fue reemplazado por el Estado-providencia del siglo XX. De ahí la oposición siempre resaltada entre un orden público clásico y otro nuevo y socializante (Robaye, 2000). Mientras que el primero es esencialmente conservador, ya que tiene como función defender los pilares de la sociedad tradicional, el segundo es innovador, por cuanto se propone cambiar la sociedad. Mientras que el primero es esencialmente negativo, toda vez que impone prohibiciones, el segundo es positivo, ya que impone obligaciones a las partes y no duda en adecuar el contenido de determinados contratos, con el propósito de orientar la actividad contractual para favorecer la economía o proteger a la parte débil.

\footnotetext{
${ }^{11}$ Este fallo admitió la nulidad de un contrato cuyo objeto era la explotación de los enfermos mediante una publicidad intensiva y el uso de calificativos destinados a impresionar al público (a pesar de que tal objeto no estaba prohibido por ningún texto) (Tribunal Grande Instance de Paris, 8 nov. 1973, D. 1975, p. 401 s, nota M. PUECH, a propósito de las buenas costumbres).
} 


\section{Referencias}

Acosta, J. (2018). Libertad, derecho y democracia: un análisis desde el paradigma del contrato (individual y social). Revista Estudios de Derecho, 75(166), 116-135.

Acosta, J. y Valderrama, F. (2015). Elementos de derecho europeo para la caracterización de las cláusulas abusivas en la contratación. Dikaion, (24)1, 12-35.

Barreyre, A. (1937). L'évolution et la crise du contrat. Université de Bordeaux.

Berlioz, G. (1976). Le contrat d'adhésion. LGDJ.

Berthiau, D. (1999). Le principe d'égalité et le droit civil des contrats. LGDJ.

Capitant, H. (1922). Les transformations du droit civil français depuis cinquante ans. Livre du Cinquantenaire de la Société de Législation Comparée. Société de Législation Comparée.

Capitant, H. (1923). De la cause des obligations. Dalloz.

Capitant, H. (1934). Le régime de la violation du contrat. Dalloz Hebdomadaire, 1.

Catala, P. (Dir). (2005). Avant-projet de réforme du droit des obligations et de la prescription. Documento oficial de Francia.

Catala, P. (2008). Deux regards inhabituels sur la cause dans les contrats. Défrenois, 21,2365 .

Cedras, J. (2003). Liberté, égalité, contrat. Le solidarisme contractuel en doctrine et devant la Cour de cassation. Cour de Cassation. https://www.courdecassation.fr/publications 26/rapport annuel 36/rapport 200 3 37/deuxieme partie tudes documents 40/tudes diverses 43 /doctrine devant 6260.html

Chabas, J. (1931). De la déclaration de volonté en droit civil français. Sirey.

Chénédé, F. (2008). L'utilité de la cause de l'obligation en droit contemporain des contrats: l'apport du droit administratif. Contrats, Concurrence, Consommation, 11.

Chevreau, E, Mausen, Y. y Bouglé, C. (2007). Introduction historique au droit des obligations. Litec.

Colin, P. (1897). Théorie de la cause dans les obligations conventionnelles. [Tesis doctoral, Université de Paris]. Repositorio institucional Université de Paris. 
Conseil Constitutionnel [CC], Décision n ${ }^{\circ}$ 97-388 DC du 20 mars 1997. Rec. 97388. Marzo 20, 1997 [Fran.].

Constitución Política de Colombia [C.P.]. Art.1. Julio 7 de 1991 (Colom.).

Corte Constitucional de Colombia [C.C.], noviembre 28, 1996, M.P.: C. Gaviria Díaz. Sentencia C-66o/96, [Colom.]

Corte Casación. Diciembre 13, 1929. Com., Civ., S. 1931.1.49 note P. [Fran.].

Corte Casación. Septiembre 13, 2011, D.2011.2518, note L. d'Avout et N. Borga, RTD civ. 2012.113, obs. B. Fages [Fran.].

Corte Suprema de Justicia [C.S.J.], Sala de Casación Civil, febrero 21, 2012, M.P. W. Namén Vargas, Sentencia SC284-2006, [Colom.].

De Saint-Rémy, R. 1928. De la révision des clauses léonines dans les contrats d'adhésion. [Tesis doctoral, Université de Paris]. Repositorio institucional Université de Paris.

Dereux, G. (1910). De la nature juridique des contrats d'adhésion. Sirey.

Dikoff, L. (1938). L'évolution de la notion de contrat. En Mélanges Capitant (pp. 201-217). Duchemin-Dalloz.

Dollat, J. (1905). Les contrats d'adhésion. [Tesis doctoral, Université de Paris]. Repositorio institucional de la Université de Paris.

Domergue, M. (1935). Étude d'ensemble sur le contrat d'adhésion. [Tesis doctoral, Université de Toulouse]. Repositorio institucional Université de Toulouse. https://gallica.bnf.fr/ark:/12148/bpt6k9790629j.texteImage

Dubreueil, L. (1919). Des mobiles dans les contrats. [Tesis doctoral, Université de Lyon]. Repositorio institucional de la Université de Lyon.

Duguit, L. (2018) [1912]. Les transformations générales du droit privé depuis le Code Napoléon. Hachette.

Durand, P. (1944). La contrainte légale dans la formation du rapport contractuel. Revue Trimestrielle de Droit Civil, 6, 73-81.

Durkheim, E. (1991) [1930]. De la division sociale du travail. Quadrige/PUF.

Fabre-Magnan, M. (2008). Réforme du droit des contrats: "Un très bon projet”. $L a$ Semaine Juridique: Juris-classeur périodique, 43(1), 13-16.

Ferrand, F. (1997). Droit privé allemand. Dalloz.

Revista IUSTA

ISSN: 1900-0448 | e-ISSN: 2500-5286 | DOI: https://doi.org/10.15332/25005286

N. ${ }^{0} 55$ | julio-diciembre del 2021 
Fouillé, A. (1885). La science sociale contemporaine. Hachette.

Fouillé, A. (1909). L’idée moderne du droit. Hachette.

Gahdoun, P.-Y. (2008). La liberté contractuelle dans la jurisprudence du Conseil constitutionnel. Dalloz.

Gaudemet, E. (1898). Étude sur le transport de dettes à titre particulier. Librairie Nouvelle de Droit et de Jurisprudence.

Gaudin de Lagrange, E. (1935). L’intervention du juge dans le contrat. Sirey.

Gazzaniga, J.-L. (1992). Introduction historique au droit des obligations. PUF.

Ghestin, J. (1984). L'ordre public, notion à contenu variable en droit privé français. En C. Perelman y R. Vander Elst (Dirs.), Les notions à contenu variable en droit (pp. 7794). Centre National de Recherches de Logique.

Ghozi, A. y Lequette, Y. (2008). La réforme du droit des contrats : brèves observations sur le projet de la chancellerie. Recueil Dalloz, 37(7354), 2609.

Gounot, E. (1912). Le principe de l'autonomie de la volonté. Contribution à l'étude critique de l'individualisme juridique. Rousseau.

Gual, J., (2015). Las cláusulas de irresponsabilidad (entre asimetría, equilibrio y abusividad). Universidad Católica de Colombia.

Hauriou, M. (1906). L’institution et le droit statutaire. Recueil de Législation de Toulouse, 135 .

Hauriou, M. (1927). L’ordre social, la justice et le droit. Revue Trimestrielle de Droit Civil, 795 .

Hauser, J. (2003). L'ordre public et les bonnes mœurs. En P. Remy-Corlay y D. Fenouillet (Eds.), Les concepts contractuels français à l'heure des Principes du droit européen des contrats (pp. 105-122). Dalloz.

Hinestrosa, F. (2015). Tratado de las obligaciones. De las fuentes de las obligaciones: el negocio jurídico. Universidad Externado de Colombia.

Huc, T. (1894). Commentaire du Code civil. Cotillon.

Ihéring, R. (1969). L'esprit du droit romain dans les diverses phases de son existence. Forni. 
Izorche, M.-L. (1989). L'avènement de l'engagement unilatéral en droit privé contemporain. PUAM.

Jamin, C. (2003). Quelle nouvelle crise du contrat? Quelques mots en guise d’introduction. En C. Jamin y D. Mazeaud (Eds.), La nouvelle crise du contrat (pp. 7-14). Dalloz.

Josserand, L. (1927). De l'esprit des droits et de leur relativité, théorie dite de l'abus des droits. Rousseau.

Julliot de la Morandiere, L. (1939). L'ordre public en droit privé interne. En Etudes de Droit Civil à la mémoire d'Henri Capitant (pp. 381-404). Dalloz.

Lagarde, X. (2007). Sur l'utilité de la théorie de la cause. Recueil Dalloz, 11, 740-745.

Laurent, F. (1887). Cours élémentaire de droit civil, t. 2. Bruylant-Cristophe.

Lévy, J.-P. y Castaldo, A. (2002). Histoire du droit civil. Dalloz.

Lorenzen, E. (1919). Causa and Consideration in the Law of Contracts. Yale Law School Legal Scholaship Repository. Faculty Scholarship Series 4560. http://digitalcommons.law.yale.edu/fss papers/4560

Louis-Lucas, P. (1918). Volonté et cause. Étude sur le rôle respectif des éléments générateurs du lien obligatoire en droit privé. Sirey.

Louis-Lucas, P. (1939). L'Autonomie de la volonté en droit privé interne et en droit international privé. En C. Henry, Études de droit civil à la mémoire d'Henri Capitant (pp. 469-490). Dalloz.

Maury, J. (1920). Essai sur le rôle de la notion d'équivalence en droit civil français. [Tesis doctoral, Université de Toulouse]. Repositorio institucional Université de Toulouse.

Mazeaud, D. (2008). Réforme du droit des contrats : haro en Hérault, sur le projet ! Recueil Dalloz, 2675.

Moeneclaye, P. (1914). De la naissance du formalisme dans les obligations civiles et commerciales françaises. [Tesis doctoral, Université de Lille]. Repositorio institucional Université de Lille.

Mekki, M. (2004). L'intérêt général et le contrat. Contribution à une étude de la hiérarchie des intérêts en droit privé. LGDJ.

Missol, A. (1934). L'assurance contrat d'adhésion. [Tesis doctoral, Université de Lyon]. Repositorio institucional Université de Lyon.

Revista IUSTA

ISSN: 1900-0448 | e-ISSN: 2500-5286 | DOI: https://doi.org/10.15332/25005286

N. 055 | julio-diciembre del 2021 
Morel, R. (1950). Le contrat imposé. En Mélanges Ripert (pp. 116-134). LGDJ.

Pédamon, M. (2004). Le contrat en droit allemand. LGDJ.

Perreau, É. (1934). Une évolution vers un statut légal du contrat. En Mélanges F. Gény. (pp. 354-371). Sirey.

Picard, M. (1950). L'emprise de l'administration sur le contrat d'assurance. En Mélanges Ripert (pp. 127-135). LGDJ.

Pichon, V. (1913). Des contrats d'adhésion, leur interprétation et leur nature. [Tesis doctoral, Université de Lyon]. Repositorio institucional Université de Lyon.

Picot, Y. (1989). Le devoir de loyauté dans l'exécution du contrat. LGDJ.

Planiol, M. (1905). Traité élémentaire de droit civil français, 3 éd., t. 2. LGDJ.

Ponceau, R. (1931). La volonté dans le contrat suivant le Code civil. Rousseau.

Portier, G. (1909). Du rôle du juge dans les contrats d'adhésion. [Tesis doctoral, Université de Paris]. Repositorio institucional Université de Paris.

Ranouil, V. (1980). L'autonomie de la volonté : naissance et évolution d'un concept. PUF.

Ripert, G. (1936). Le droit de ne pas payer ses dettes. Recueil Dalloz, 15.

Robaye, R. (2000). Une histoire du droit civil. Academia Bruylant.

Rouhette, G. (1965). Contribution à l'étude critique de la notion de contrat. Université de Paris.

Roussel, G. (1936). Le contrat et l'intervention du juge et du législateur dans son exécution. LGDJ.

Saleilles, R. (1901). De la déclaration de volonté. Contribution à l'étude de l'acte juridique dans le Code civil allemand. Pichon.

Savatier, R. (1964). Les métamorphoses économiques et sociales du droit civil d'aujourd'hui. Dalloz.

Sériaux, A. (1997). L'affaire Chronopost : arrêt de principe ou accident de parcours ? Variations sur le bon usage de la notion d'obligation essentielle. Recueil Dalloz, 121.

Terré, F., Simler, P. y Lequette, Y. (2013). Droit civil. Les obligations. Dalloz.

Tison, R. (1931). Le principe de l'autonomie de la volonté dans l'ancien droit français. Loviton. 
Vargas Bernal, A. (2018). Los límites y las consecuencias reales del discurso jurídico de la autonomía privada de la voluntad en el individuo. IUSTA, 2(49), 91-114.

https://doi.org/10.15332/s1900-0448.2018.0049.04

Villalba, J. y Fernández, M. (2020). El rol de los principios del derecho de los contratos en el derecho de consumo. En J. Gual (Dir.), Los principios del derecho contractual y su extensión al derecho de consumo (pp. 23-48). Ibáñez.

Waline, M. (1949). L’individualisme et le droit. Domat-Montchrestien.

Revista IUSTA

ISSN: 1900-0448 | e-ISSN: 2500-5286 | DOI: https://doi.org/10.15332/25005286

N. 055 | julio-diciembre del 2021 